\title{
DO OUTRO LADO DA AVENIDA RIVADAVIA: O ANTI-MUNDO
}

\author{
Heloísa Helena Siqueira Correia ${ }^{1}$ \\ Valdir Aparecido de Souza ${ }^{2}$
}

\begin{abstract}
Resumo: A partir de pontuais relações entre história e literatura, as reflexões que se seguem giram em torno da construção mítica de Buenos Aires, da fronteira - sem linhas geográficas específicas, mas também com a indicação de fronteira com o Brasil - e do Sul, realizada por Jorge Luis Borges, tomando símbolos, já recorrentes na literatura argentina, como o punhal, o gaúcho oriental, o duelo e o pampa e os torna universais. No caso específico dos duelos de gaúchos com armas brancas está presente o tema do duplo, tema importante para a literatura fantástica, promovendo a intersecção de planos literários diversos; a partir de uma leitura que toma esta estética como mimesis da representação, passa-se a observar a presença da mimesis da produção, termo cunhado pelo crítico Luis Costa Lima para um tipo de mimesis que, ao invés de conjugar-se com a physis aproxima-se de uma antiphysis. A mimesis da representação está presente na fundação mítica de Buenos Aires, da fronteira e do Sul, nos contos que a concretizam e nos motivos borgeanos de tal fundação. A antiphysis, por sua vez, se pode notar em contos como " $E I$ inmortal", "El evangelio según Marcos", "Tlön, Uqbar, Orbis Tertius" e "El encuentro".
\end{abstract}

Palavras-Chave: Borges, Símbolos, Fronteira, Fantástico, Mímesis.

Resumen: A partir de relaciones específicas entre historia y literatura, las siguientes reflexiones giran en torno ala construcción mítica de Buenos Aires, de la frontera - sín rayas geograficas específicas, pero también que indica la frontera con Brasil - y del Sur, realizado por Jorge Luis Borges, él toma símbolos recurrentes en la literatura argentina, como la daga, el gaucho oriental, las pampas y el duelo y les torna universais. En el caso específico de los due-

1 Professora adjunta do Departamento de Línguas Vernáculas vinculado ao Núcleo de Ciências Humanas da Fundação Universidade Federal de Rondônia (UNIR), Porto Velho, Estado de Rondônia, Brasil; doutora em Teoria e Historia Literária pela Universidade de Campinas (UNICAMP); líder do Grupo de Pesquisa em Estudos Literários da UNIR, atualmente desenvolve o projeto "O fantástico: intersecções críticas"; integrante do GT da ANPOLL "Vertentes do insólito ficcional". Endereço eletrônico: heloisahelenah2@hot mail.com.

2 Professor adjunto do Programa de Mestrado em História e Estudos Culturais, Núcleo de Ciências Humanas, Universidade Federal de Rondônia (UNIR); doutor em História e Sociedade pela UNESP; líder do Grupo Centro Interdisciplinar de Estudos do Imaginário Social. Coordenador do projeto "Cidadania e memória: uma via de mão dupla". Endereço eletrônico:valdir@unir.br. 
los degauchoscon armas blancas esta presente el tema del doble, tema importante para la literatura fantástica, haciendo la promoción de la intersección de los distintos planes literários; desde una lectura que toma esta mimesis estética como representación, continúa con la observación de la presencia de la mimesis de la producción, un término acuñado por el crítico Luis Costa Lima para un cierto tipo de mimesis que, en lugar de combinarse con la physisacercase a unaantiphysis. La mimesis de la representación está presente en la fundación mítica de Buenos Aires, de la frontera y del Sur, en los cuentos que la encarnan y en las razones borgeanos para su fundación. La antiphysis, a su vez, se puede notar en los cuentos como "El inmortal", "El evangelio según Marcos", "Tlön, Uqbar, Orbis Tertius" y "El encuentro".

Palabras-Clave: Borges, Símbolos, Frontera, Fantástico, Mimesis.

\section{INTRODUÇÃO}

A partir de pontuais relações entre história e literatura, as reflexões que se seguem giram em torno da construção mítica de Buenos Aires, da fronteira - sem marcas geográficas específicas, mas também com a indicação de fronteira com o Brasil - e do Sul, realizada por Jorge Luís Borges, demonstrando que nos duelos de gaúchos com armas brancas está presente o tema do duplo, tema caro à literatura fantástica, promovendo a intersecção de planos literários diversos; a partir de uma leitura que toma esta estética como mimesis da representação, passa-se a observar a presença da mimesis da produção, termo cunhado pelo crítico Luis Costa Lima para um tipo de mimesis que, ao invés de conjugar-se com a physis aproxima-se de uma antiphysis.

A mimesis da representação está presente na fundação mítica de Buenos Aires, da fronteira e do Sul, nos contos que a concretizam e nos motivos borgeanos de tal fundação. A antiphysis, por sua vez, se pode notar em contos como "El inmortal"," El evangelio según Marcos", "Tlön, Uqbar, Orbis Tertius" e "El encuentro". Seria ingênuo desconsiderar o caráter labiríntico da obra de Borges, e as análises já consolidadas de sua obra por inúmeras chaves e vieses de leitura. Entretanto, aos nos debruçarmos sobre as paisa- gens míticas e a anthiphysis torna-se possível apresentar uma breve contri- buição na miríade de análises existentes.

Em Borges, a fronteira e o Sulsão míticos; deslocados por um século no tempo serviriam a Borges para fortalecer seu projeto de universalização das cores locais argentinas. Uma fronteira arquetípica que comporta um 
passado imemorial, um Sul inalterado, muito além de um espaço concreto a ser integrado ou transformado.

A fixidez da imagem da fronteira e do Sul serve ao seu projeto modernizante, tanto da literatura argentina, quanto da política de seu país. E promove uma ressignificação que desloca os arredores, tanto da capital quanto do pampa, para outras partes do mundo, permitindo sua universalização, bem comofaz a arte operar também como critica à política conservadora.Curiosamente, enquanto para os brasileiros o pampa significa liberdade e autonomia, as imagens do pampa formuladas por Borges são sinônimo de espaço violento, barbárie e terra sem lei, uma materialização ao sul dofar-westestadunidense.

Paradoxalmente, ao projetar de forma irônica a fronteira com o Brasil e representá-la simbolicamente enquanto perigo de retorno à barbárie, a fronteira é o local de fuga de todos os personagens, se a capital portenha é a síntese, a fronteira é o local de revelação, da verdade única de todos. Esta marca levou alguns promotores culturais brasileiros desavisados e com leitura superficial de Borges a questionar o escritor acerca da presença de um suposto tom pejorativo em relação ao Brasil. Provocações ingênuas, obviamente nunca respondidas por Borges.

Borges nomeava a fronteira com o Brasil, de Banda Oriental (Uruguai) - artifício usado, segundo o crítico literário uruguaio PabloRocca, para conferir um tom épico a sua ficção - justamente por sua postura crítica em relação ao suposto nacionalismo presente nas obras dos grandes escritores argentinos apoiado na presença do regionalismo e da cor local, de caráter mais político que literário. Essa narrativa que pretendia projetar-se como identidade política buscava no pampa oriental, na llanura, na orilla e no gaucho elementos de construção do que Borges considerava uma "coesão artificial", o que não cabia no projeto literário universalizante do escritor.

O regionalismo interessava para uma reduzidíssima elite política porteña, sem significados ou sentidosque emanassem do próprio gaucho; antes, tratava-sede abundante descrição barroca da cor local, muito distante da realidade. Borges busca se desviar desta searaprópria aos escritores "oficiais" como Guiraldes, Sarmiento e outros. Sua estética, diferentemente, cria um plano mítico para os personagens/arquétipos de mí Buenos Aires e da pampa, retirando-os do regionalismo e alçando-os ao plano da atemporalidade. Desse modo, se distancia da literatura oficial encomendada pelos interesses do poder. 
O mito do Sul e da fronteira para sempre consagrado por Borges nas imagens dos gaúchos, dos duelos e do pampa e as refinadas construções intelectuais, apoiadas em raciocínios metafísicos e argumentos teológicos, além da vasta, vária e frequente referência a escritores canônicos e não canônicos incomodam à crítica dos anos 40 e 50, ávida por encontrar a essência da argentinidade e a defesa dos valores humanos. O crítico Luís Costa Lima desvenda, entre os motivos de tal rejeição, a criação da antiphysis por Borges (LIMA, s.d.). Este "outro" da physis franqueia ao leitor a criação de, efetivamente, outro mundo. Neste mundo o mito é outro e a realidade é outra.

Ao criar o plano mítico, o escritor alça o Sur à categoria de objeto literário universal. Neste toposqualquer llanura, planície, pampa, deserto produzem a mesma vertigem horizontal. Espaço revelador da pequenez humana e ao mesmo tempo denunciadordo elemento humano estranho a ela, pois não há como se esconder do destino no deserto, é preciso enfrentá-lo. Além disso, opampa é o lugar de revelação do verdadeiro eu primitivo do argentino.

O temor da barbárie é tema caro ao povo argentino, a visão de conquista manifestada em Sarmiento, por exemplo, sempre foi pelo extermínio dos povos ameríndios. Borges afasta-se dessa literatura regionalista imposta pelos cânones da época e,fazendo da fronteira uma marca própria, cria o artifício necessário para conviver com a perseguição política e com a consciência de que era um escritor marginal em relação ao circuito europeu (SARLO, 1998).

Ao mesmo tempo em que a construção borgeana da fronteira e do Sul tem um caráter mítico, é possível dizer que as encruzilhadas que se bifurcam no Borges histórico, escritor de carne-e-osso, são as mesmas veredas de todos os latino-americanos, órfãos da paternidade exótica e sem raiz cultural de sua maternidade nativa. Neste entremeio, o gaucho representa a própria condição do sul-americano, portador de uma identidade móvel e empreendedor de uma busca que o faz procurar a si mesmo sempre no mesmo lugar: aqui.

\section{A FUNDAÇÃO MÍTICA DE BUENOS AIRES}

É sabido que Buenos Aires tem duas fundações e dois nomes:Puerto de Nuestra Senhora Santa Maria de Buen Aire, nome dado por Pedro de Mendoza em 1531,e Santisima Treindad, nome concedido à cidade por Juan 
de Garay em 1580. Buenos Aires faz parte do ciclo de desventura analisado pela Professora Beatriz PastorBodmer (1992) nos discursos de conquista, a cidade seria uma das contrapartes mitificadas no discurso do fracasso da conquista. Sua origem polêmica é bastante evidente nas crônicas de Miranda, um dos informadores de Pedro Mendoza. Sua adjetivação e comparação a uma jovem ameríndia bem traduz as dificuldades dos conquistadores,Buenos Aires

[...] sería la concreción material de ese desventajoso proceso marital que refieren los versos de Miranda. Lo más significativo del poema radica, sin duda, en la progresión adjetival con que cierne el poeta esa "idea" de ciudad que representa en ese momento Buenos Aires: «ingrata», "desleal», «enemiga de marido», «manceba»y, sobre todo, «traidora» (OÑATE, 2001, p. 43).

A segunda fundação teve caráter oficial, com cerimonial de posse e discurso do General Juan de Garay, que a refundava para ser entreposto entre Assunção e Europa. Garay inclusive intencionava apagar o nome dado por Pedro de Mendoza, associado à brujería nativa, para Santíssima Trindade,

[...]pongo su asbocacion de la Santísima trenidad la q. sea y a de ser yglesia mayor e perroquial contenida e señalada en la traga que tengo hecha de la dha. ciudad y la dha. ciudad mando que se yntitule la ciudad de la trenidad [...] y en señal de poseçion hecho mano a su espada y corto hieruas y tiro cuchillada (OÑATE, 2001, p. 47) ${ }^{3}$.

Como afirma o historiador argentino Ricardo Majó Framis, se Garay criou a estrutura física, Pedro de Mendoza havia fundado mais que uma cidade: uma ideia platônica de cidade. A partir da porta entreaberta por Mendoza, iniciamos nossa breve análise sobre a fundação borgiana de Buenos Aires.

Diante dessa história mais épica que civilizatória, Borges faz uma inversão de 360 graus na Buenos Aires de Miranda, criando na ficção uma cidade idealizada. Ele a constrói como sinônimo de urbanidade e centro irradiador de cultura, enquanto o pampa é visto como atraso e abrigo de criminosos. Há uma clara dicotomia entre porto, urbano, democrático e civilizado versus pampa, rural, caudilhismo e barbárie.

3 Segundo o autor este texto aqui reproduzido "es copia del traslado existente en el Archi- vo General de Indias. Sevilla. Sección VI. Escribanía de Cámara. Legajo 846, folios 132 a 134 vto.". Citado por José Torre Revello, "Acta de fundación de la ciudad de Buenos Ai- res", Exposición Ibero-Americana, Sevilla, s/f, s/n. 
Paralelamente à construção mítica de uma fronteira com o Brasil, alicerçe para seu projeto universalizante, construiuuma Buenos Aires pelo resgate saudosista da cidade que vivera na infância. Criada para se contrapor a cidade real, febril e cheia de tensões; os conflitos ficavam reservados a fronteira oriental com o Brasil. Os surtos de violência e barbárie se localizavam para além da avenida Rivadavia.

\begin{abstract}
Aunque a veces nos humille algún rascacielos, la visión total de Buenos Aires no es whitmaniana.

Las líneas horizontales vencen las verticales. Las perspectivas de casitas de un piso alienadas y confrontándose a lo largo de las leguas de asfalto y piedras son demasiado fáciles para no parecer inverosímiles. En cada encrucijada se adivinan cuatro correctos horizontes (BORGES apud OÑATE, 2001, p. 179).
\end{abstract}

Em seu retorno da Europa em 1921, Borges não encontrou maisa cidade que havia deixado; são notórias as suas declarações, e as imagens contidas em Fervor de Buenos Aires, sobre seu desencanto em relação ao crescimento e à perda das feições semicoloniais da cidade que mantinha consigo. As ruas, os pátios e os saguões estavam sendo engolidos pela arquitetura moderna e tornando-se uma desagradável paisagem para Borges.Buenos Aires torna-se o palco dos seus dilemas, como no conto "La fiesta del monstruo" - um libelo crítico ao general Perón que circulava na clandestinidade entre os amigos. Na perda de Buenos Aires, Montevidéu passa a ser vista como a capital de ayer preservada, projeção cênica de muitos outros enredos numa cidade que estava além da real, Enfrente.

Buenos Aires se transformou de maneira vertiginosa entre os anos 10 e 30. Essa modernização galopante veio acompanhada de uma turba ruidosa de imigrantes que passou a dominar a cena cultural portenha. A cidade mudava sua face a cada segundo, finalmente deixava de ser crioula para se tornar cosmopolita. Desejando preservá-la na ficção, a solução borgeana foi mitificá-la no passado. Para Sarlo, Borges intencionava ressignificar esteticamente a experiência crioula do passado,

En el caso de Borges y de otros vanguardistas porteños se observa claramente el movimiento para otorgarle al pasado una nueva función. $Y$ el debate comienza sobre el significado del pasado: hay que hacer una nueva lectura de la tradición. Borges avanza: hay que retomarla y pervertirla (SARLO, 1998, p. 48). 
Ainda em relação à capital do porto, essa mudança será deveras encarada como perniciosa cultural e socialmente. Para resolver esse problema Borges lança mão de um projeto que,segundo Sarlo,visava responder às demandas impostas pela economia e pela urbanização acelerada,

Afectados por el cambio, inmersos en una ciudad que ya no era la de su infancia, obligados a reconocer la presencia de hombres y mujeres que, al ser diferentes, fracturaban una unidad originaria imaginada, sintiéndose distintos, en otros casos, a las elites letradas de origen hispano-criollo, los intelectuales de Buenos Aires intentaron responder, de manera figurada o rectamente, a un interrogante que organizaba el orden del día: ¿cómo imponer (o cómo aniquilar) la diferencia de saberes, de lenguas y de prácticas? ¿cómo construir una hegemonía para el proceso en el que todos participaban, con los conflictos y las vacilaciones de una sociedad en transformación? La literatura da forma a estas preguntas, en un período de incertidumbres que obligaban a leer de manera distinta el legado del siglo

XIX. Pero lacultura de Buenos Aires estaba, de todos modos, impulsada definitivamente por el vendaval de lo nuevo, aunque muchos intelectuales lamentaran la dirección o la naturaleza de los cambios. Por eso, la modernidad fue un escenario donde también anclaron fantasías de restauración y sentimientos nostálgicos (SARLO, 1998, p. 50).

Não havia retornoda modernização da cidade, antes orgulhosa do porto e que se projetava como embaixada da cultura européia se espraiando sobre os pampas, agora era ruidosamente uma metrópole fervilhando de imigrantes trabalhadores com ideologias fascistas e comunistas; e uma nascente cultura de massas que desconhecia toda a discussão sobre o duelo, o gaucho, o caudilho, o punhal e a fronteira com o Brasil.

Borges realizou a fundação mítica pra dar substrato a essa Buenos $\mathrm{Ai}$ res que lhe fugia à vista, somente conseguindo percebê-la de modo fugaz pelo movimento extremamente acelerado da metrópole que engolia $\mathrm{Pa}$ lermo, Rivadavia, o Parque dos Bosques e outras imagens de sua infância. Em seu poema "Fundación Mítica de Buenos Aires", a fundação da cidade ideal e a memória de sua infância se fundem num mesmo ato mítico:

Prendieron unos ranchos trémulos en la costa, durmieron extrañados. Dicen que en el Riachuelo, pero son embelecos fraguados en la Boca.

Fue una manzana entera y en mí barrio: en Palermo (BORGES, 1994, p. 81).

Os elementos de natureza conferem um tom mítico e sagrado à fundação, e o escritor ainda ironiza a memória e a tradição que são figurados por ele como "enganos"; na "verdade" o lugar primordial se localizava no bairro de Palermo em que havia crescido. $O$ escritor ressignifica a memória 
crioula e a canaliza para o plano ficcional literário. Opção que aproxima o poema dos relatos de conquistadores como Colombo, Pizarro e Cortez. Enquanto aqueles produziam relatos oníricos para Vossa Alteza e para garantir a posse das Índias, Borges mitifica a capital para torná-la atemporal. 0 caráter mítico é reforçado por elementos da natureza, como no verso a seguir:

A mi se me hace cuento que empezó Buenos Aires:

la juzgo tan eterna como el agua y el aire (BORGES, 1994, p. 81).

E também pelo reconhecimento do limite humano diante de algo que é pré-existente ao homem, segundo suas palavras,

[...] aquí mis pasos

Urden su incalculable laberinto (BORGES, 1993, p. 325).

Semelhante aos relatos dos primeiros conquistadores que associavam elementos naturais às visões paradisíacas de riquezas descomunais, Borges reconstrói o seu tesouro de infância num poema mítico, uma Bue- nos Aires que estava além da história e da memória. Como ali sempre este- ve,a cidade perduraria mesmo com a rapidez de seus trens e a arrogância dos arranha-céus que surgiam. Eventos insignificantes diante de sua exis- tência atemporal. Se na criação de Buenos Aires reaparece o discurso miti-ficador, ao criar a fronteira Sul o discurso que ressurge é o mesmo do fra- casso da conquista (BODMER, 1992, p. 126).

\section{A CRIAÇÃO MÍTICA DA FRONTEIRA E DO SUL: O DUELO FANTÁSTICO}

É possível perceber como Borges aproveita-se de símbolos, já recorrentes na literatura argentina, que remetem à fronteira e ao Sul para mitifica-los em direção à sua universalização. Lança mão de signos fortes para o imaginário argentino como o punhal, o gaúcho oriental, o duelo e o pampa. Sua estratégia é elevar hiperbolicamente os símbolos para se diferenciar dos escritores regionalistas preocupados com a identidade nacional.

Segundo Sarlo (1998, p. 70-71), Borges apontava Dom Segundo Sombra como exemplo de obra carregada de cores locais. O conto borgeano "Evangelho segundo Marcos" é exemplar neste sentido, pois a leitura de Dom Segundo Sombra, pela personagem, para uma família de gaúchos, não encontra ressonância; a família não reconhece o personagem gaúcho de Guiraldes como um gaúcho verossímil. Neste sentido Borges demonstra que uma obra que se pretende fiel à realidade pode dela muito se afastar. 
O escritor transcende a discussão sobre os aspectos históricos e culturais, pois sua preocupação é com a criação da obra como artifício e não como reflexo da realidade.

Em direção oposta, é possível perceber que o autor recorre, em outros momentos, a fatos reais, como o assassinato que presenciou em Rivera, fronteira com Santana do Livramento, Rio Grande do Sul. Potencializando a literatura como artifício e recorrendo ou não a fatos reais, percebe-se facilmente que o gaúcho presente na obra de Borges é diverso do gaúcho presente nas obras de Echeverría, Sarmiento e Hernandez. Borges, aliás subverte a perspectiva ao transformá-lo em tipo mítico, cuja vida é, muitas vezes, condensada e eternizada em um único instante revelador.

O Sul, presença incólume na obra borgeana, prescinde do tempo tal como o mito. Para sempre os leitores sabem que o Sul está suspenso, estática presença construída com imagens imóveis de duelos, de gaúchos íntimos da planície, da fronteira e da vida áspera. Em "El Sur", conto da obra Fiç̧ões, a personagem Dhalmann vislumbra um gaúcho no interior de um armazém. A imagem impressiona por seu caráter definitivo:

Enel suelo, apoyado en el mostrador, se acurrucaba, inmóvil como una cosa, un hombre muy viejo. Los muchos años lo habían reducido y pulido como las aguas a una piedra o las generaciones de los hombres a una sentencia. Era oscuro, chico y resseco, y estaba como fuera del tempo, enuna eternidade (BORGES, 1994, p. 528).

No homem imóvel o signo eterno do Sul. Na sequência do mesmo conto o poder fundamental do Sul, materializado na figura do gaúcho, convoca a personagem Dahlmannà peleja. A esse respeito, não será demais retomar as palavras do narrador do conto:

Desde unrincón, el viejo gaúcho extático, en el que Dahlmann vio una cifra del Sur (del Sur que era suyo), le tiro una daga desnuda que vino a caer a sus pies.

Era como si el Sur hubiera resuelto que Dahlmannaceptara el duelo.

[...] Dahlmann empuña con firmeza el cuchillo, que acaso no sabrá manejar, y sale a la llanura (BORGES, 1994, p. 529-530).

Juan Dahlmann, secretário de uma biblioteca municipal em Buenos Aires, que se sente "[...] hondamente argentino [...]", escolhe seu crioulismo. Descendente de duas linhagens: seu avô paterno era pastor evangélico e germânico, seu avô materno, um soldado que morreu flechado por índios, Dahlmann escolhe a linhagem materna e sua americanidade.

O conto "El fín",também do livro Ficções, demonstra, segundo Beatriz Sarlo, como Borges se relaciona com a tradição, na medida em que o conto 
reescreve o destino da mítica personagem Martín Fierro, do poema homônimo de Hernández. No poema épico, Fierro mata um negro e tempos depois vence Moreno, o irmão do morto em uma payada; no conto borgeano, Fierro encontra Moreno sete anos depois, a dívida de sangue os une e os faz se reencontrarem. Na narrativa borgeana Martín Fierro morre em peleja com Moreno. Nas palavras de Sarlo:

Al presentar la muerte en duelo de Martín Fierro, Borges también mata al personaje más famoso de la literatura argentina. Así responde a la pregunta estética e ideológica acerca de qué debe hacer un escritor con la tradición: su propia inserción en el ciclo gauchesco zanja la cuéstion de manera original. Borges enfrenta el texto fundamental (el texto sagrado) y tiece su ficción con los hillos que Hernández habia dejado sueltos; la historia de Fierro es representada, escrita en prosa, incluso parafraseada, y, al mismo tempo, modificada para siempre (SARLO, 1998, p. 93).

A relação da obra com a tradição é de traição, com a ressalva de que é a figura dupla do duelo que se torna mítica e permanece para sempre, entre Fierro e Moreno, entre Dahlmann e o homem que o provoca em um armazém. EntreDahlmann e Fierro há, ainda, uma diferença que salta aos olhos. Em "El Sur", a personagem, ao escolher sua linhagemmaterna, abre a possibilidade do duelo; em "El fín", o heroico Fierro não pode escolher frente à dívida que contraiu com Moreno, seu código moral o impele ao duelo, sem alternativas ou outros caminhos possíveis. Fierro chega a pedir desculpas a Moreno por tê-lo feito esperar tantos anos. Moreno e Martín Fierro são duplos um do outro. Sarlo, ao analisar a relação entre as personagens e entre o poema de Hernández e o conto de Borges, explica que a morte de Fierro:

\footnotetext{
[...] nos es una muerte cualquiera, porque Fierro es derrotado por alguien que no había podido derrotarlo en el poema de Hernández: un Moreno, un hombre de la raza que Fierro había insultado.

Estas relaciones entre el poema y el cuentose complican cuando, en las ultimas frases, Borges cruza el tema (universal, fantástico) del doble com su reescritura del Martín fierro (SARLO, 1998, p. 92).
}

O tema fantástico do duplo é também o duplo do homem: herói e vencido, insultador da raça negra e negro. Nesse sentido, a estudiosa consegue demonstrar a intersecção entre as pelejas, tão semelhantes às pelejas reais, e o fantástico literário, abrindo a perspectiva e a possibilidade de pensar a identidade como, no mínimo, dupla, mas por certo, plural. Na narrativa de "El fín" encontra-se o momento de explicitação do duplo: 
Inmóvil, el negro parecia vigilar su agonía laboriosa. Limpió el facón ensangrentado en el pasto y volvió a las casas con lentitud, sin mirar para atrás. Cumplida su tarea de justiceiro, ahora era nadie. Mejor dicho era el outro: no tenía destino sobre la tierra y había matadoa un hombre (BORGES, 1998, p. 521).

O duelo e o duplo testemunham a violência, o heroísmo sem sentido e o nada da existência. Tema primeiramente localizado em dois elementos, em outros momentos da obratorna-se universal. Não são poucas as passagens em que Borges atrela o individual ao universal, seja pela repetição, pelos homens, de atos semelhantes, seja pela operação da leitura.

Em "Biografía de Tadeo Isidoro Cruz", do livro El Aleph,a posição de Borges em relação à personagem de Hernández é explicitada: considera-o um desertor. E um desertor que, no conto, inspira a deserção de Cruz, em uma clara inversão dos valores e virtudes nacionalistas que, em geral, se espera encontrar nos heróis e modelos nacionais de conduta. Deserção, heroísmo e violência se avizinham neste conto. Cruz e Fierro, como Moreno e Martín Fierro, vivem como duplos. A narrativa borgeana explicita a presença do duplo quando Cruz:

\section{[...] mientras combatía en la oscuridad (mientras su cuerpo combatia en la oscuridad), empezó a compreender. Comprendió que un destino no es mejor que outro, pero que todo hombre debe acatar o que lleva adentro. Comprendió que las jientas y el uniforme ya lo estorbaban. Comprendió su intimo destino de lobo, no de perro gragario; comprendió que el outro era el (BORGES, 1994, p. 563).}

A personagem Cruz, assassino que pagara sua dívida e tornara-se soldado, reencontra sua identidade ao se deparar com Fierro. O destino de lobo o atrai irrestivelmente, de modo que o mito vence a razão reformado- ra e civilizadora.A identidade de ambas as personagens é sentida como um destino, algo inevitável e possuidor de sentido.

Em vários textos, de modo recorrente, Borges trabalha com o tema do duplo, tema que ele mesmo, em Conferência de 1949, proferida em Montevideo, segundo o crítico uruguaio Emír Rodrigues Monegal, elege como um dos procedimentos da literatura fantástica: "[...] la obra de arte dentro de la misma obra, la contaminación de la realidade por el sueño, el viaje en el tempo, el doble" (MONEGAL, s. d., p. 83). Contos como "25 de Agosto, 1983" da coletâneaLa memoria de Shakespeare e"El outro", de El libro de arena, são modelares ao tornarem explícitas as estratégias de encontro dos duplos. 
Em "25 de Agosto, 1983" percebe-se o duplo distante dos duelos à faca e entranhado no fantástico literário. Nesta narrativa que se desenrola em sonho, a personagem Borges encontra-se com outra personagem, Bor-ges, em uma viagem temporal e espacial, em que o duelo é a tênue conver- sa afiada entre ambas as personagens. Um acabara de completar 61 anos, o outro, já cumprira 84 anos de vida e está prestes a morrer por suicídio. Em "El otro", por sua vez, o sonho obnubila também o tema da viagem temporal. O encontro entre Borges jovem e Borges idoso cria o ambiente de juventude e sabedoria da narrativa, e novamente o leitor está às voltas com o duplo fantástico e o duelo de palavras, duelo que diferente do que é travado em nome da honra, não tem vencedor.

Isto posto, o que está em questão é certa espécie de continuidade que se pode entrever entre as narrativas em torno de homens que duela- mem uma pulperia, ousob o céu aberto do pampa, e o duplo do ser; o eu que se reconhece duplo e uno simultaneamente ou que se encontracom o outro também ele mesmo- pelo sonho ou pela viagem tempo- ral \espacial. Por isso, em "Utopía de un hombre que está cansado", incluído também em El libro de arena, os olhos do leitor brilham ao se depararem com o momento em que a personagem narrador, viajante do tempo e que se auto denomina Borges, inicia a narrativa referindo-se ao pampa:

No hay dos cerros iguales, pero en cualquier lugar de la tierra la llanura es una y la misma. Yo iba por un caminho de la llanura. Me pregunté sin mucha curiosidade si estaba en Oklahoma o en Texas o enla región que los literatos llaman la pampa. Ni a derecha ni a izquierda vi um alambrado. Como otras veces repetí despacio estas líneas, de Emilio Oribe:

En médio de la pânica llanura interminable

Y cerca del Brasil,

Que van creciendo y agrandándose (BORGES, 1994a, p. 52).

Em meio às possibilidades geográficas nota-se, pelas linhas citadas,a preferência pela planície próxima do Brasil, o pampa. A viagem temporal que, segunda a narrativa, é também sempre uma viagem espacial, leva-o a uma planície que lhe faz sentir-se em meio ao pampa, demonstrando, neste caso, que o pampa está no futuro, como está no passado literário forjado por Borges com amatéria mítica.

Outra duplicidade, agora de natureza e cultura, pode ser flagrada no conto "Historia del guerrero y de la cautiva", do livro El aleph, que ilumina a curta historia do encontro, ocorrido duas vezes, entre a avó inglesa do narrador e uma jovem mulher inglesa, índia loura de olhos azuis, que vive no 
Pampa ou Tierra Adentro, região sob domínio indígena. Segundo as pala- vras do narrador: "Quizá las dos mujeres por un instante se sintieron her-manas, estaban lejos de su isla querida y en un increíble pais" (BORGES, 1994, p. 559). A aludida irmandade, no entanto, não se sustenta ao longo do conto quando o leitor passa a conhecer a dimensão fatídica e a dimen- são voluntariosa da existência da jovem personagem. Indagada pela avó inglesa do narrador Borges, a jovem:

Dijo que era de Yorkshire, que sus padres emigraron a Buenos Aires, que los había perdido en el malón, que la habían llevado los índios y que ahora era mujer de um capitanejo, a quién ya había dado dos hijos y que era muy valiente. Eso lo fue diciendo enun inglés rustico, entreverado de araucano o de pampa, y detrás del relato se vislumbraba una vida feral: los toldos de cuerode caballo, las hogueras de estiércol, los festines de carne chamuscada o de vísceras crudas, las sigilosas marchas al alba; el asalto de los corrales, el alarido y el saqueo, la guerra, el caudaloso arreo de las haciendas por jin etes desnudos, la poligamia, la hediondez y la magia. A esa barbárie se había rebajado una inglesa. Movida por la lástima y el escândalo, mi abuela la exhortó a no volver. Juró ampararla, juro rescatar a sus hijos. La otra le contestó que era feliz y volvió, esa noche, al desierto (BORGES, 1994, p. 559).

A jovem inglesa, índia loura, faz lembrar Dhalmann, personagem de "EI sur", ela também escolhe entre suas linhagens a que lhe fala no íntimo. Do ponto de vista da avó, esposa de Francisco Borges, chefe das fronteiras Norte e Oeste de Buenos Aires, a jovem vive uma vida selvagem, bárbara; a menção à magia não deixa de ser importante, uma vez que se trata de um ponto de vista inglês, civilizatório e metropolitano.

A irmandade momentânea que deu lugar à escolha pela vida sul americana apenas retorna na percepção da avó, que, após a morte de seu marido "[...] pudo percibir en la otra mujer, también arrebatada y transformada por este continente implacable, un espejo monstruoso de su destino..." (BORGES, 1994, p. 559). Na sequencia da narrativa, no entanto, novamente a irmandade de desfaz e predomina o estranhamento entre ambas e a escolha diversa, pela personagem, de seu próprio destino. A seguir, as palavras do texto:

Sín embargo, se vieron outra vez. Mi abuela había salido a cazar; en un rancho, cerca de los bañados, un hombre degollaba una oveja. Como en un sueño, pasó la índia a caballo. Se tiró al suelo y bebió la sangre caliente. No sé si lo hizo porque ya no podia obrar de outro modo, o como un desafio y un signo (BORGES, 1994, p. 559). 
A imagem não poderia ser mais performática, a cativa que não é mais cativa bebe o sangue quente da ovelha recém abatida e o texto se pergunta sobre os motivos. A dupla pergunta sugere a dupla resposta, a índia de olhos azuis assim age porque só pode agir desse modo e sua ação é um desafio e um signo. Desafio à outra personagem, à razão e à civilização, e signo da vida selvagem e instintiva. Em todas as respostas, está a força da vida americana com sua, no mínimo,dupla cultura e dupla raça, e a ênfase na mítica vida selvagem.

Em "El evangelio según Marcos" da mesma coletânea El informe de Brodie, Borges radicaliza a questão da relação com a América e a vida rústica. O conto em questão narra a história de Baltasar Espinosa, um estudante de medicina que aceita o convite de seu primo, Daniel, para passar uma temporada em uma estância no campo. Durante período em que o primo se ausenta da propriedade, Espinosa passa a conviver apenas com o capa- taz, Gutre, e sua família. Trata-se também do momento em que são assola- dos pelas chuvas e o estudante se vê cercado por uma inundação. A história do capataz e sua família é descoberta por Espinosa nas páginas finais de uma Bíblia escrita em língua inglesa:

En las páginas finales los Guthrie - tal era su nombre genuíno - habían dejado escrito su historia. Eran oriundos de Inverness, habían arribado a este continente, sin duda como peones, a princípios del siglo diecinueve, y se habían cruzado con los índios. La crónica cesaba hacia mil ochocientos setenta y tantos; ya no sabían escribir. Al cabo de unas pocas generaciones habían olvidado el inglês; el castellano, cuando Espinosa los conoció, les daba trabajo. Carecían de fe, pero em su sangre perduraban, como rastros oscuros, el duro fanatismo del calvinista y las supersticiones del pampa (BORGES, 1993, p. 448).

Essa mistura de "duro fanatismo del calvinista", "supersticiones del pampa" e desconhecimento da língua que possibilita as relações sociais conduz as ações das personagens de modo inesperado. Após Baltasar ler o Evangelho segundo Marcos para os Guthrie e ter percebido que o seguiam pelo corredor e pelos cômodos da casa, em uma noite recebe a visita da jovem da família em seu quarto e silencia a respeito do fato. O pai da família, então, pergunta a Baltasar sobreo motivo da morte de Cristo, segue a resposta e o curto diálogo entre ambas as personagens:

- Sí. Para salvar a todos del infierno.

Gutre le dijo entonces.

- Qué es el infierno? 
- Un lugar bajo tierra donde las animas arderán y arderán.

- Y también se salvaron los romanos que lo clavaron em la cruz?

- Sí - replicó Espinosa, cuya teologia era incierta (BORGES, 1993, p. 449).

Após a intimidade com a jovem da família Gutre e o esclarecimento dado ao pai, o leitor já desconfia que algo terrível poderá acontecer, mas nem de longe imagina o que a narrativa reserva de fato. Será a realização,a mais próxima possível, do sentido literal do texto que o estudante lera e relera ao capataz e sua família. Próximos também de uma cultura de matriz não ocidental, e tendo já esquecido muito de sua origem inglesa, as personagens podem ler o grande livro do cânone ocidental de modo nunca antes visto, de modo a repetir as ações narradas no Evangelho segundo Marcos, tornando-as reais:

Los três los habían seguido. Hincados enel piso de piedra le pedieron la bendición. Después lo maldijeron, lo escupieron y lo empujaron hasta el fondo. La muchacha lloraba. Cuando abrieron la puerta, vio el firmamento. Um pájaro grito; pensó: Es um jilguero. El galpón estaba sin techo; habían arrancado las vigas para construir la Cruz (BORGES, 1993, p. 450).

Ironicamente, enquanto milhares de fiéis leem o texto sagrado supostamente realizando em suas vidas os ensinamentos de Cristo e imitando suas virtudes, os leitores ouvintes da leitura de Baltasar compreendem realmente o mais importante do texto: a crucificação redentora. Por isso colocará em prática o rito sacrificial e imitarão o assassinato promovido pelos vilões romanos. Demonstra assim, certa faceta cruel que pode haver na mímeses. Baltasar será sacrificado.

\section{MÍMESES DA PRODUÇÃO E ANTIPHYSIS}

Que tipo de mímeses encontra-se na matéria da literatura fantástica borgeana?Segundo o estudioso LuísCosta Lima não será, em toda a obra, a mímeses da representação. Deve-se levar consideração que subjacente ao conceito de mímeses localiza-se o conceito grego de physis que, no pensamento dos filósofos pré-socráticos, possui três grandes sentidos: "1)processo de nascimento, surgimento ou origem de todas as coisas; 2 ) substância física da qual são feitas todas as coisas; 3 ) princípio eterno res- ponsável pela geração, organização e estruturação das coisas existentes. (MACIEL JUNIOR, 2003, p. 156). No pensamento de Aristóteles, o conceito configura-se como possuidor de perfeição. Lima assim explica a perfeição suposta pelo estagirita: "A physis não abrange apenas o que se patenteia, o 

- Un lugar bajo tierra donde las animas arderán y arderán.

- Y también se salvaron los romanos que lo clavaron em la cruz?

- Sí - replicó Espinosa, cuya teologia era incierta (BORGES, 1993, p. 449).

Após a intimidade com a jovem da família Gutre e o esclarecimento dado ao pai, o leitor já desconfia que algo terrível poderá acontecer, mas nem de longe imagina o que a narrativa reserva de fato. Será a realização,a mais próxima possível, do sentido literal do texto que o estudante lera e relera ao capataz e sua família. Próximos também de uma cultura de matriz não ocidental, e tendo já esquecido muito de sua origem inglesa, as personagens podem ler o grande livro do cânone ocidental de modo nunca antes visto, de modo a repetir as ações narradas no Evangelho segundo Marcos, tornando-as reais:

Los três los habían seguido. Hincados enel piso de piedra le pedieron la bendición. Después lo maldijeron, lo escupieron y lo empujaron hasta el fondo. La muchacha lloraba. Cuando abrieron la puerta, vio el firmamento. Um pájaro grito; pensó: Es um jilguero. El galpón estaba sin techo; habían arrancado las vigas para construir la Cruz (BORGES, 1993, p. 450).

Ironicamente, enquanto milhares de fiéis leem o texto sagrado supostamente realizando em suas vidas os ensinamentos de Cristo e imitando suas virtudes, os leitores ouvintes da leitura de Baltasar compreendem realmente o mais importante do texto: a crucificação redentora. Por isso colocará em prática o rito sacrificial e imitarão o assassinato promovido pelos vilões romanos. Demonstra assim, certa faceta cruel que pode haver na mímeses. Baltasar será sacrificado.

\section{MÍMESES DA PRODUÇÃO E ANTIPHYSIS}

Que tipo de mímeses encontra-se na matéria da literatura fantástica borgeana?Segundo o estudioso LuísCosta Lima não será, em toda a obra, a mímeses da representação. Deve-se levar consideração que subjacente ao conceito de mímeses localiza-se o conceito grego de physis que, no pensamento dos filósofos pré-socráticos, possui três grandes sentidos: "1)processo de nascimento, surgimento ou origem de todas as coisas; 2 ) substância física da qual são feitas todas as coisas; 3 ) princípio eterno res- ponsável pela geração, organização e estruturação das coisas existentes. (MACIEL JUNIOR, 2003, p. 156). No pensamento de Aristóteles, o conceito configura-se como possuidor de perfeição. Lima assim explica a perfeição suposta pelo estagirita: "A physis não abrange apenas o que se patenteia, o 
que está atualizado, mas também o que nas coisas subsiste em estado de potência" (LIMA, s.d., p. 288).

A mímeses que movimenta a obra borgeana nem sempre se conjuga à physis, antes remete, isto sim, àquilo que o crítico Luís Costa Lima deno- mina mímeses de uma antiphysis. "Ou seja, que tem por fundamento o pressuposto de que nenhum penhor nos garante a qualidade do mundo, de que ele é um simulacro ou uma ilusão, senão mesmo algo que precisaria ser substituído por outro mundo" (LIMA, s. d., p. 289). Trata-se de uma natureza em que o melhor não está presente mas sim as coisas em sua imperfeição, em seu sem sentido vertiginoso, nas cercanias ou mesmo no seio do nada.

Se, como afirma Betriz Sarlo, nas historias de invenções alheias deHistoria universal de la infâmia, encontra-se a originalidade borgeana e que "Después de estos cuentos, Borges es ya definitivamente Borges" (SARLO, 1998, p. 118), o que se seguirá é a continua assunção de seu caminho de leitor e escritor não canônico, não tradicional e que parte das orillas de uma só vez para o outro lado do mundo, o lado não luminoso de potências que não necessariamente se dirigem ao melhor ou à perfeição. Lima reconhece a antiphysis primeiramente em determinada leitura e apropriação que Bor-ges faz da sabedoria gnóstica, cujos pressupostos envoltos na criação do mundo e do homem apoiam-se na suposta existência de uma criação im- perfeita, levada a cabo por um deus inferior, subalterno e secundário (LIMA, s. d.).

Essas nossas supostas raízes permanecem ao rés do chão, ao sabor das intempéries, e não são incorporadas pela obra borgeana, segundo o crítico, de modo religioso, fiel ou supersticioso. Interessa a Borges internali-zar em sua obra o modelo de articulação dos argumentos gnósticos que tornam evidentes o erro, a morte, o nada que há em nós e no mundo. Isto lhe serve ficcionalmente para a configuração de relatos assombrosos e insó- litos que não oferecem respostas aos leitores, nem ao menos alguma dire- ção. Eis o vetor escolhido pelo escritor: a literatura sem missão de melho- ramento, sem proporcionar formação, evolução ou civilização. Sua concepção de literatura leva-a para longe de sentidos redentores e eleva- doresque a tornam apenas um meio para o homem. Sua antiphysis é o que é de modo multiplicado e intrincado, labiríntico e especular: participa do que a physis cobre, vela, do queo logos esconde, desvia de si mesmo.

Não será por isso que o personagem Martín Fierro, ainda que antiherói e desertor, traidor e assassino, acaba por morrer? - a morte da qual 
se esconde a razão age seguidamente, um dos agentes da antiphysis poderosa e incontornável. O personagem Baltasar promove a revivescência do poder salvador de Cristo, mas o que salta aos olhos do leitor não é a exuberância ou grandiosidade do ato, e sim a morte, simples, definida. Duelos sem vencedores e com duplicidades que dinamizam identidades, intercambiando-as e apagando o sentido do duelo, demonstram a frivolidade da honra, da coragem e da morte.

De acordo, então, com Lima, Jorge Luís Borges produz, durante grande parte de sua obra, no âmbito da mímeses da produção - mímeses da antiphysis - e não da representação. Ao tratar da obre de Mallarmé, o crítico explica a diferença conceitual do seguinte modo:

\begin{abstract}
[...] toda obra que não tem nem uma relação direta, nem a possibilidade de um efeito direto sobre o real, só poderá ser recebida como de ordem mimética, seja por representar um Ser previamente configurado - mímesis da representação - seja por produzir uma dimensão do Ser - mímesis da produção. [...] Convém ainda esclarecer: para que uma obra da segunda espécie possa ser acolhida pelo leitor é preciso que contenha indicadores do referente que desfaz. A categoria da negação é assim necessariamente ressaltada, muito embora o trabalho da produção vá além do negado. A negação importa como lastro orientador da recepção, a qual se pretende conhecer o objeto, e não só entender seu comportamento, precisa ver o que se faz com o que se negou (LIMA, 2003, p. 182).
\end{abstract}

Aí está a indicação do trabalho usual do leitor da obra borgeana que reconhece conteúdos, raciocínios, figuras, conceitos, imagens, personagens e valores da grande cultura, e passo a passo começa a perceber que são apenas aparenciais, linhas fantasmais da razão iluminista, personagens de outra verve. A personagem Homero de "El inmortal", "[...] después de cantar la guerra de llión, cantó la guerra de las ranas y los ratones" (BORGES, 1994, p. 540). A outra personagem, Marco Flaminio Rufo, o imortal, anseia pela morte porque sabe que a imortalidade é irrelevante.

A crucificação anunciada em "El evangelio según Marcos" é um assassinato que, originariamente ocorrido em um pequeno país tomado por Roma, será repetido em um pequeno país marginal. Deus é deus da imperfeição e do erro, não é a origem da ideia de perfeição que existe em nós; pode ser um sonho, um pesadelo humano ou a reverberação de uma ideia. A literatura nasce do mito inventado da fronteira e do Sul em duelo, com gaúchos e suas armas brancas. E no momento de criação desse mito, século $X X$, não existem mais os gaúchos do modo como o mito os apresentam; já não mais vivem duelando ou pelejando pelo pampa. Mito criado no século 
passado, anacronicamente insiste em figurar personagens históricas do século XIX argentino.

Um dos ápices da mímeses da produção que se movimenta pela antiphysispode ser identificado no conto"Tlön, Uqbar, Orbis Tertius", do livro Ficções. O conto narra a história da descoberta, pelas personagens Borges e Casares, de um novo planeta, com a descrição de seus hemisférios, sua geografia, arqueologia, literatura e filosofia, suas torres de sangue e seus tigres transparentes. É preciso ter em conta o risco de a leitura relacionar tal planeta com o nosso, de modo direto ou alegórico. Neste ponto, é preci- so interpor novamente as reflexões do estudioso Luís Costa Lima:

[...] a base na antiphysis elimina a presença maciça do alegórico. Com isso, entretanto, não pretendemos insinuar que os relatos de Borges constituam dominantemente exemplos de performatividade. Procuremos dizê-lo melhor: ao passo que na mímeses da representação, a alegoria é o limite "alto", i. e., aquele a que tende o processo interpretativo, em Borges a alegoria tem seu lugar deslocado: na maioria dos casos, ela é apenas o ponto de partida para a comunicação do texto (LIMA, s.d., p. 296).

Na narrativa, o leitor reconhece alegoricamente as marcas da grande cultura presentes na menção a grandes filósofos, seus pensamentos e ideias, na referência ao poder do império americano, na riqueza e papel das enciclopédias para o conhecimento humano, no relato de técnicas humanas determinantes para o avanço da ciência e de linguagens convencionais e eficazes, entre outros elementos. Entretanto, como explica o crítico brasileiro acima mencionado, ao se referir a "La loteria en Babilonia":"A antiphysis, portanto, não engendra alegorias, porque antes significa a exploração irônica e paradoxal dos avessos de nosso mundo da physis". Ela avança por cadeias performativas, i.e., que realizam atos e ações e não simplesmente os descreve ou constata (LIMA, s. d., p. 297). Se o leitor começa a ler reconhecendo alegorias, sua mente logo percebe a negação, ponto de partida da mímesis da produção: o absurdo do idealismo e do empirismo filosóficos em ação, o comportamento ridiculamente hiperbólico dos americanos, a arqueologia que procura aquilo mesmo - objetos - que inventou; a ausência do substantivo no idioma do hemisfério sul, a ausência de verbo e substantivo no idioma do hemisfério norte;linguagens arbitrárias que obedecem à arbitrariedade e pluralidade das crenças humanas.

Em meio a um cenário inflado de elementos, figurações e encenações aparentemente dignos da icônica cultura ocidental, Borges nada descortina ou revela. E como um prestidigitadormenciona o Brasil como país de ori- 
gem do volume da enciclopédia que contém a história de Tlön. A menção ao Brasil franqueia a grandeza, o outro lado da fronteira, o desconhecido e próximo a um só tempo, o estrangeiro. Mas em Tlön, nem Tlön é o que parece, nem nossa realidade é o que diz ser. A enciclopédia foi remetida do Brasil, pelo correio, à personagem inglesa Herbert Asher. O inglês já estava morto e nunca recebeu a remessa. Tlön seria um planeta inventado por intelectuais europeus, norte-americanos e sul-americanos, todos ironizados, parodiados e glosados pelo conto.

Aprimeira intromissão dos objetos de Tlön em nosso mundo refere- se ao aparecimento de uma bússola e a segunda intromissão diz respeito a um objeto cujo dono veio da fronteira, sem país específico, sem pátria, sem filiação. Segundo as palavras do conto acerca da mencionada intromissão:

Ocurrió unos meses después, en la pulpería de un brasileiro, en la Cuchilla Negra. Amorim y yo regresábamos, de Sant'anna. Una creciente del río Tacuarembó nos obligó a probar (y a sobrellevar) esa rudimentar hospitalidad. El pulpero nos acomodó unos catres crujientes en una pieza grande, entorpecida de barriles y cueros. [...] En el delírio se le habian caído del tirados unas cuantas monedas, y un cono de metal reluciente, del diâmetro de un dado. Em vano unchico trato de recoger ese cono. Un hombre apenas acertó a levantarlo. Yo lo tuve en la palma de la mano algunos minutos: recuerdo que su peso era intolerable y que después de retirado el cono, la opresión perduró. También recuerdo el círculo preciso que me grabo en la carne. Esa evidencia de un objeto muychico y a la vez pesadíssimo dejaba la impresión desagradable de asco y de medo. Un paisano propus que lo tiraran ao río correntoso. Amorim lo adquirió mediante unos pesos. Nadie sabía nada del muerto, salvo "que venía de la frontera". Esos conos pequeños y muy pesados (hechos de un metal que no es de este mundo) son imagen de la divinidad, en ciertas religiones de Tlon (BORGES, 1994, p. 14-15).

A simultaneidade de peso enorme e tamanho diminuto do objeto, sua impressão sobre a palma da mão, os efeitos de asco e medo, sua inuti- lidade trocada por uns poucos pesos, sua natureza que não é deste mundo, ligado ao fato de desempenhar o papel de divindade para as religiões de Tlöno tornamum objeto fantástico, algo inexplicável para os padrões da física moderna, mas não talvez, para a física contemporânea, que investiga densidades. A anthiphysis, nesse momento, parte da negação irônica do processo de vinculação entre o não-saberhumano e o divino, revivendo um argumento simples da antropologia e dos estudos facilitadores das explicações em torno do surgimento do mito. 
O escritor argentino faz a antiphysis operar inclusive sobre o mítico duelo que sua obra consagrara em narrativas temperadas pela coragem e violência. Borges em "El encuentro" do livro El informe de Brodie, Borges transfere o protagonismo mítico dos duelos humanos para as armas brancas. No conto, encontra-se a narração de um duelo entre Duncan e Uriarte após desentendimento em um jogo de cartas.

O ponto de vista narrativo fica por conta de um garoto de nove ou dez anos que momentos antes do início da peleja, enquanto os homens ainda jogavam cartas, explora a casa que ambienta a partida de baralho e descobre uma vitrine com facas. A mesma vitrine oferecerá as armas para a peleja. Após golpear fatalmente Duncan, Uriarte Ihe pede perdão; o que se segue entre os presentes, amigos dos duelistas, é um acordo acerca do melhor modo de levar a história a público: como um duelo de espadas e não de facas. E em uma reviravolta tipicamente borgeana a narrativa não cessa, antes prossegue criando outros motivos do duelo e outros protago- nistas.

Quando o narrador, após tantos anos, resolve contar a história do duelo sobre a qual havia jurado segredo, fá-lo ao comissário José Olave, quem lhe esclarece que as armas com as quais havia se admirado na vitrine, e que depois deram força ao duelo, são armas de Juan Almanza e Juan Almada. Estes homens nunca se encontraram embora tenham se procurado mutuamente para pelejar; Almanza morreu devido a uma bala perdida e Almada por razões naturais. Após essa informação, o conto desvenda a história mais determinante que a historia do desentendimento entre Duncan e Uriarte, a história das armas:

Nueve o diez hombres, que ya han muerto, vieron lo que vieron mis ojos - la
larga estocada en el cuerpo y el cuerpo bajo el cielo - pero el fin de otra
historia más antigua fue lo que vieron. Maneco Uriarte no mato a Duncan; las
armas, no los hombres, pelearon. Habían dormido, lado a lado, en una vitrina,
hasta que las manos las despertaron. Acaso se agitaron al despertar; por eso
tembló el puño de Uriarte, por eso tembló el puño de Duncan. Las dos sabían
pelear - no sus instrumentos, los hombres - y pelearon bien esa noche. Se
habían buscado largamente, por los largos caminhos de la província, y por fin
se encontraron, cuando sus gaúchos ya eran polvo. En su hierro dormia y
acechaba un rencor humano.
Las cosas duran más que la gente. Quién sabe si la historia concluye aqui, quién
sabe si no volverán a encontrarse (BORGES, 1993, p. 421).

Nesse sentido, o duelo é plasmado pela antiphys, não pela continuidade do duplo, mas pelo protagonismo das armas brancas, personagens de 
uma história mais antiga e determinante, em que os homens são os instrumentos, os meios para que as armas realizem seu fim: a peleja, na qual são mestras. Por trás da mítica peleja humana, uma peleja de objetos poderosos e inquietos que tornam os homens vazios de honra ou coragem, agora apenas títeres sem expressividade autônoma. É, então, a criação mítica que se altera, contrariando a natureza inalterável do mito, e se torna outra ao retirar do homem o protagonismo da ação.

Borges realiza radicalmente o que, em outro sentido, havia declarado em "El escritor argentino y la tradición", quando afirma que nós, os sul americanos, "[...] podemos manejar todos los temas europeos, manejarlos sin supersticiones, con una irreverencia que puede tener, y ya tiene, consecuencias afortunadas" (BORGES, 1994, p. 273). Apenas que, no caso específico de sua literatura, perde-se de vista a fundação mítica da cultura ocidental logo repudiada pela razão, eencontra-se a fundação mítica da literatura argentina, coordenada por mitos apenas literários, que não portam a força mítica nos mesmos moldes dos mitos histórico-culturais e se auto declaram invenções; e a physis que participa do mito e sustém o logos grego é vencida pela antiphysis, francamente imperfeita, sem progressão, força de negatividade franca e frontal. Movendo-se na mímeses da produção, Borges produz uma dimensão do ser: um mundo sul americano.

\section{REFERÊNCIAS}

BODMER, Beatriz Pastor. The Armature of Conquest: Spanish Accounts of the Discovery of America, 1492-1589. Redwood: Stanford University Press, 1992.

BORGES, Jorge Luis. Fervor de Buenos Aires. In: Obras completas: 1923-1949. Buenos Aires: Emecé Editores, 1994, p. 11-74.

BORGES, Jorge Luis. Fundación Mítica de Buenos Aires. In: Obras completas: 1923-1949. Buenos Aires: Emecé Editores, 1994, p. 81.

BORGES, Jorge Luis. Tlon, Uqbar, Orbis Tertius. In: Obras completas: 19231949. Buenos Aires: Emecé Editores, 1994, p. 431-443.

BORGES, Jorge Luis. El fín. In: Obras completas: 1923-1949. Buenos Aires: Emecé Editores, 1994, p. 519-521.

BORGES, Jorge Luis. El Sur. In: Obras completas: 1923-1949. Buenos Aires: Emecé Editores, 1994, p. 525-530.

BORGES, Jorge Luis. El inmortal. In: Obras completas: 1923-1949. Buenos Aires: Emecé Editores, 1994, p. 533-544.

BORGES, Jorge Luis. Historia del guerrero y de la cativa. In: Obras completas: 1923-1949. Buenos Aires: Emecé Editores, 1994, p. 557-560. 
BORGES, Jorge Luis. Biografía de Tadeo Isidoro Cruz (1829-1874). In: Obras completas: 1923-1949. Buenos Aires: Emecé Editores, 1994, p. 561-563.

BORGES, Jorge Luis. 25 de Agosto, 1983. In: Obras completas: 1975-1985. Buenos Aires: Emecé Editores, 1994a, p. 377-380.

BORGES, Jorge Luis. El otro. In: Obras completas: 1975-1985. Buenos Aires: Emecé Editores, 1994a, p. 11-16.

BORGES, Jorge Luis. Utopía de un hombre que está cansado. In: Obras completas: 1975-1985. Buenos Aires: Emecé Editores, 1994a, p. 52-56.

BORGES, Jorge Luis. Buenos Aires. In: Obras completas: 1952-1972. Buenos Aires: Emecé Editores, 1993, p. 325.

BORGES, Jorge Luis. El encuentro. In: Obras completas: 1952-1972. Buenos Aires: Emecé Editores, 1993, p. 417-421.

BORGES, Jorge Luis. El Evangelio según Marcos. In: Obras completas: 19521972. Buenos Aires: Emecé Editores, 1993, p. 446-450.

FRAMIS, Ricardo Majó. Vidas de los navegantes, conquistadores y colonizadores españoles de los siglos XVI, XVII y XVIII. Madrid: Aguilar, 1963, p. 1212. (Tomo II).

LIMA, Luis Costa. Mímesis e modernidade: formas das sombras. São Paulo: Paz e Terra, 2003.

LIMA, Luis Costa. O fingidor e o censor: no ancien regime, no iluminismo e hoje. Rio de Janeiro: Forense Universitária, s.d.

MACIEL JÚNIOR, Auterives. Pré-socráticos - a invenção da razão. São Paulo: Odysseus Editora, 2003. (Imortais da Ciência).

MONEGAL, Emir Rodriguez. Narradores de esta America. Montevideo: Alfa, s.d.

OÑATE, Pedro Mendíola. Buenos Aires entre dos calles: Breve panorama de la vanguardia poética argentina. Cuadernos de América sin Nombre, no 4, Murcia, Universidad de Alicante, 2001.

ROCCA, Pablo. Uma literatura de fronteira: Jorge Luis Borges, fiç̧ões e debates. O Eixo e a Roda. Belo Horizonte, v. 18, n. 2, p. 123-142, jul./dez. 2009. Disponível em: http://www.letras.ufmg.br/poslit/08_publicacoes_pgs/Eixo\%20e\%20a\%20Ro da\%2018,\%20n2/07-Pablo-Rocca.pdf. Acesso em: 20 nov. 2013.

SARLO, Beatriz. Borges, un escritor en las orillas. Buenos Aires: Ariel, 1998. 